however, we think is right since the author states in his preface 'the aim of the book has been to approach psychological medicine as an integral part of general medicine rather than as a special or separate subject.'

The young medical registrar or practitioner will find chapters on gastroduodenal function and peptic ulcer, asthma, skin reactions and cutaneous disease, vasomotor effects of emotional activity, psychological factors and rheumatism, and psychological aspects of phthisis well written and informative. For these sections alone the book is thoroughly worth while.

There is a useful bibliography at the end of each chapter.

R.S.O.

\section{MCCLUNG'S HANDBOOK OF MICROSCOPICAL TECHNIQUE}

Edited by Ruth McClung Jones. 3rd Edition. Pp. xix +790 , with 157 illustrations. London: Cassell and Co. 1950. £4 ros.

This well-known work, though extensively modified in this edition, still retains its familiar attributes, though some of the older material has been omitted (notably the botanical section); the relative strengths and weal nesses of the earlier editions are still apparent. This is in no sense a derogatory statement; in a work of this magnitude, dealing with such a debatable subject, it is virtually impossible to avoid a somewhat patchy distribution of effort. The chapter devoted to blood is especially good, and an already good treatment has been improved and considerably enlarged. On the other hand, the cytological methods are very poorly dealt with, and the extremely valuable aceto-carmine squash method is not even mentioned. The connective tissues have been much better treated than in the previous edition, though the use of gallamine blue for the demonstration of calcium is not mentioned. The various techniques for the study of teeth are very amply described, and the chapter on the central nervous system also represents an advance on the previous high standard. Peripheral nerves and nerve endings are less fully treated; it is unfortunate that no reference is made to the Janus green method of Couteaux for motor end plates.

The sections on polarized light, micromanipulation and microincineration are excellent, but the phase contrast, electron microscopy and fluorescence microscopy are not quite to such a high standard. There are also sections devoted to experimental embryology, vital staining, autoradiography, transillumination, the centrifuge microscope and protozoology.

It can be seen from the above list that the whole subject of microscopical technique is very extensively covered and it would be unreasonable to expect all these subjects to be equally well presented. One feature that might well have been included is a review of the optics of microscopic vision, with especial reference to resolution, and its limitations; the very clear exposition of the physical principles of polarized light indicates that such a physical $\varrho$ subject can be quite adequately described in a work $\frac{3}{\infty}$ of this type.

\section{PSYCHOSOCIAL MEDICINE}

By James L. Halliday, M.D., D.P.H. Pp. 277. London: William Heinemann. I948. $17 \mathrm{~s}$. $6 \mathrm{~d}$.

This is an ambitious book as it deals with all $\mathbb{\otimes}$ manners of social ills, discussing psychology, psychiatry, birth statistics, economics, politics, etc. To the reviewer the most important part is the $\overrightarrow{0}$ second one on psychosomatic medicine. Here the environmental, social, economic and cultural in- $\vec{\omega}$ fluences on psychosomatic affections are treated. $\frac{\Omega}{0}$ To give some examples; the changes in sex in- $\frac{0}{7}$ cidence of a disease like exophthalmic goitre or 3 . diabetes suggest to the author a developing " neutral- iv ization in the psychological aspect of sexual dis- $\dot{\omega}$ tinction.' The changes of the educational and $\varnothing_{\infty}$ parental influences from Victorian times to the $\omega$ I930s are discussed with obvious knowledge of $\vec{A}$ psychodynamic theories. The psychosomatic as- $\frac{\dot{d}}{\sigma}$ pects of chronic and recurrent illnesses are also 우 dealt with. In the third part the author turns to the sick society. The birth rate and the psychosomatic $\vec{c}$ affection rate are taken as indices of psychological $\subsetneq$ health and it is shown that this is often going in the $\overparen{D}$ opposite direction to the physical health as measureg $\overrightarrow{0}$ by such figures as general death rate, infant mo tality, tuberculosis rate, etc. Britain as a whole, an her mining community in particular, are taken examples of sick societies. The book is stimulating and controversial.

S.L.L.

\section{HANDBOOK OF DIAGNOSIS AND TREATMENT OF VENEREAL DISEASES}

By A. E. W. McLachlan, M.B., Ch.B.(Edin.), D.P.H., F.R.S.(Edin.). 4th Edition. Pp. 368 . Edinburgh: E. \& S. Livingstone, Ltd. I95I. I 7s. 6d. net.

The fourth edition of this work maintains the high standard of its predecessors. The book is o well printed and bound and is profusely illustrated. The clinical features, differential diagnoses and 0 treatment of the venereal diseases are concisely and lucidly presented, controversial points being as far $\frac{7}{0}$ as possible avoided, as becomes a volume designed as an introduction to the subject. The social $N$ aspects are largely omitted, as the title implies. The place of penicillin in the treatment of these diseases is well discussed and references are made to the $\underset{\omega}{\tilde{W}}$ probable spheres of usefulness of some of the more recently introduced antibiotics. The great majority of the numerous illustrations are excellent, those in colour being particularly instructive. Certain of the black and white pictures should be replaced in future editions, however. The book can be thoroughly recommended as a practical guide to the student and general practitioner. 